\title{
Floodability: A New Paradigm for Designing Urban Drainage and Achieving Sustainable Urban Growth
}

\section{Goffredo La Loggia ${ }^{1} \cdot$ Valeria Puleo $^{1} \cdot$ Gabriele Freni $^{2}$}

Received: 27 November 2019 / Accepted: 13 July 2020/

Published online: 20 July 2020

(C) The Author(s) 2020

\begin{abstract}
For a large part of human history, urbanization was focused on two main objectives: defence and resource harvesting. The first objective was always achieved in a broad sense, i.e., defending the population from other humans and from natural events. Focusing on human activities, this defensive approach was also applied to urban drainage, which resulted in a systematic underestimation of the impacts of urbanization on natural systems. Environmental sustainability was introduced in an attempt to mitigate these impacts, as they had the potential to endanger future developments; thus, the possibility that urban floods may be the lesser evil was accepted. Resilience was then introduced to improve not only defence of urban areas but also their ability to recover from negative events, even though physical resilience is not always accompanied by social resilience. This paper attempts to address the philosophy of urban drainage design, introducing the new concept of floodability as an evolution of flood resilience by identifying its requirements and drivers and by using real examples to present the new concept.
\end{abstract}

Keywords Flooding risk $\cdot$ Mitigation measures $\cdot$ Sustainable urban drainage systems · Floodproofing

Valeria Puleo

valeria.puleo@unipa.it

Goffredo La Loggia

goffredo.laloggia@unipa.it

Gabriele Freni

gabriele.freni@unikore.it

1 Dipartimento di Ingegneria, Università degli Studi di Palermo, Palermo 90100, Italia

2 Facoltà di Ingegneria e Architettura, Università degli studi di Enna Kore, Enna 94100, Italia 


\section{Introduction}

Floods, which currently occur all over the world, are a common problem for urban settlements that insist upon developing within floodable areas; this problem emphasizes the need to pursue special actions related to urban drainage that redesign socioeconomic development and mitigate against the negative effects of flooding events.

Following Pasi (2016), the hazard rate of urban drainage systems has always been adjusted to accommodate for the needs of urban development (i.e., "design against nature" or the resistance paradigm) and rarely vice versa (i.e., "design with nature" or the resilience paradigm). The evolution of urban drainage management paradigms has been addressed by several researchers (Novotný 2008; La Loggia et al. 2011; Fletcher et al. 2015), and the readers of this study can refer to these contributions for a detailed review.

Therefore, a paradigm shift is needed in urban drainage design to achieve the new priority of sharing the risk of hazards by adopting spatial planning at the neighbourhood scale (Pasi et al. 2018; Serre et al. 2018) and to develop new strategies for flood risk management, thus achieving resilient and floodable cities. It is important to analyse urban vulnerabilities, considering all existing flood-hazardous areas at the local scale, making use of geospatial and related technologies to reduce uncertainty and increase the level of detail incorporated in analyses, and attempting to bridge all the gaps caused by these vulnerabilities using a multidisciplinary approach (Pasi 2016).

If we define a city's flood resilience as its capacity to move along development trajectories after the occurrence of flood events, floodability may be considered a consequential condition that emerges from the developmental process shaped by the ability of a city to forestall, recognize, adapt to, and learn from the changes, instabilities, disturbances, and calamities that may damage things that people care about (Aven and Renn 2009). From this perspective, in addition to assessing and reducing flood risk, an urban flood management system must facilitate the training of people who drive the region's responses to actual floods and who enable its recovery afterward (Sörensen et al. 2016) by evolving it to a new equilibrium.

This paper aims to outline a framework that assesses the applicability of floodability measures to urban areas, attempting to identify the key factors able to lead to real (potential) success and to highlight a path to sustainable urban growth. Recent literature has focused on flood resilience by examining either infrastructure or society without a comprehensive discussion on the ways in which social and technical factors affect one another. The floodability concept that is discussed in this paper aims to integrate these two aspects, thus showing how a region's proneness to flooding can drive new growth. Prior to the introduction of two real cases, the floodability concept is presented. Finally, some considerations and conclusions are drawn.

\section{Sustainable Urban Drainage Evolution: the Way Forward}

Considered alone, a resilient design seeks to reduce householder vulnerability by implementing precautionary measures or adaptation strategies that increase resilience through an initial intervention in society.

As pointed out in the literature, people who live in areas subject to natural hazards often do not learn from their experiences, which is in contrast to the widespread concept that populations who undergo recurring risk are more prepared to face risky situations (Siegrist and Gutscher 2008). On the other hand, people's comprehension of and reactions to natural events 
are governed by several complex factors (Harvatt et al. 2011). In general, a lack of direct personal experience involving natural events lessens an individual's comprehension of such events and constrains his or her motivation to take personal action. A person's tendency to take limited action when facing risk might come from his or her social vulnerabilities; these vulnerabilities increase the fragility of some individuals when they face particular threat. For these reasons, it is important to create people-oriented management strategies that focus on vulnerable groups, recognize local capacities, foster communication and create awareness campaigns to empower citizens and mitigate the undesirable effects of natural events (Roder 2019). People living in floodable areas have to know how to prepare for floods and how to behave during such events.

To accelerate the progress of urban areas and of society within this new growth path, it is important to evaluate the ways in which the flooding of transport infrastructures, public utilities and service facilities (i.e., schools and hospitals) can affect people's lives. As shown by Viero et al. (2019), the exposure analysis demonstrates that flood risk is not appropriately considered in the context of land-use planning, nor is it suitably understood by the residents of areas at risk of low-probability but high-impact flooding events.

Often, the economy is the main driver of this progress rather than ecology, in which environmental and human activities are perceived to be part of a unique system; recent development has rarely relied on a holistic and long-term vision. For this reason, some authors have shown the economic advantages of local decentralized flood mitigation measures in terms of water resource saving and rain water harvesting (Coombes and Barry 2008; Freni and Liuzzo 2019). These studies often state that such practices are not affordable when considering the simple economic balance between construction costs and resource saving; however, they mention that these practices become accessible if analysed within a broader framework, such as the one proposed in the present paper, that looks at additional externalities at the property scale such as flood damage prevention, landscaping value and increases in private property value.

Even though resource harvesting during flooding events may have potential at the local scale, the majority of urban planning studies fail to examine this concept, as the direct and indirect damage that it causes has greater economic impacts at the urban scale. Menoni et al. (2002) proposed a method for the evaluation of the systemic vulnerability of a territorial system at the regional scale. In particular, they emphasized the need to assess the vulnerability of these systems due to the possibility of lifeline failure in the case of earthquake events and to measure, through spatial analysis, the function of the public transport infrastructures and structures in a city system, enabling the proper selection of the types and locations of mitigation interventions. Sdao et al. (2013) analysed the connections between operative centres and industries as well as those between roads and private buildings that faced risks involving landslide or flood events through physical damage and functional relationships. Based on GIS analysis, Pasi et al. (2018) developed accessibility measures through the analysis of road networks. A residential proximity to facilities and services contributes to individuals' wellbeing, and it can be theorized that this proximity improves accessibility in the case of flood events.

Following this idea, land use mapping, digital surface models, rainfall forecasts, routine asset inspections and maintenance, and stakeholder and customer reports can help to provide, even in real time, information about the response of an urban drainage system to a flood event. An interesting review regarding opportunities to use citizens' observations for flooding models was presented by Assumpção et al. (2018). Moreover, efforts are needed to increase people's confidence in flood-related planning, risk management and recovery processes (Neville and Coats 2009). The well-informed use of social media can spread information to the population 
to raise interest, to activate personnel or group initiatives and to reduce the lag time between the initiation of emergency actions and the attainment of the population's full commitment. Increasing the population's awareness of the related risks can further the evolution of urban drainage paradigms.

\subsection{The Floodability Concept}

Floodability can be defined as flood tolerance and can thus be integrated with flood resilience (akin to ecological resilience (Holling 1973)). Flood resilience is defined as the ability of a system to recover from a flood event; floodability can be defined as the ability of a system to withstand floods that occur in a part of or in the whole system while still maintaining a sufficient level of operation, thus moving to a new equilibrium among population- and staterelated variables in which flooding can be tolerated. The differences between floodability and flood resilience are found in two of their aspects: (1) floodable systems maintain a sufficient level of operation during flooding events, while resilient systems may accept temporary partial or total lapses in operation, providing that the system's recovery time is sufficiently rapid for it to return to its previous condition; (2) after relevant flooding events, floodable systems may not recover their previous state as do resilient systems but may evolve to a new equilibrium that is more adapted to flooding.

Floodability can be considered an independent paradigm that is an evolution of resilience or a facilitating strategy that introduces and achieves environmental sustainability in cases where the economic, social and cultural conditions do not allow for a green revolution.

Flood tolerance should be applied not only on a physical basis (i.e., structures and infrastructures that are designed to reduce damage and accelerate recovery) but also on societal, cultural and economic bases (i.e., orienting the society and all its interactions toward reducing the impacts of floods and facilitating recovery); it can also be a measure of the capacity of an urban system to avoid significant physical damage to vital areas as well as socioeconomic disruptions during a flood event through the adjustment of its structure (Liao 2012).

Floodable cities incorporate resistant and resilient designs in that the development of a new, sustainable form of growth must incorporate the redesign of each area, subsystem and service in light of its role in the system. A floodable system does not necessarily consist only of floodable subsystems; rather, it is a well-informed aggregation of resistant, resilient and floodable subsystems. Vital unique infrastructures should be either moved outside of floodable areas or defended because there is no other option for their survival; introducing redundancy and teaching the population to adopt this concept in terms of services involving mobility, resource supply or social activities will dramatically reduce recovery time, keep recovery initiatives inside the affected community and limit external interventions to the sectors in which the local forces are unable to accomplish recovery alone. Floodable land can be introduced, thus bringing new environmental, recreative and social functions to areas that may otherwise become unused and abandoned due to frequent flooding.

There is a need to rethink open spaces and infrastructures in ways that enable areas to convey and store flood water during wet seasons; collect diverse functional elements that are flexible in terms of operation; and modify strategic services so that they are redundant, elevated, floatable, or water-proof, thus making these services operational during flooding events and able to support recovery after the event. 
Design in the context of flooding risk ideally entails the creation of connections among human and natural processes as well as among different disciplinary fields. Moreover, spatial urban design must be developed as a negotiation platform upon which all the involved stakeholders act consciously as "flood designers".

Populations should be trained to prepare themselves and to adapt their properties and activities to the possibility of flood events, thus evolving to "live with floods". Again, when considering urban evolution, floodability may be viewed as a stand-alone paradigm or a supporting action that allows for environmental sustainability in areas that are not economically, socially and/or culturally ready for green re-design.

Floodability makes resilience-based management adaptive and is a learning-by-doing process: a floodable city is always a work in progress.

To enhance urban floodability, the investments made in both flood prevention and flood recovery must be integrated with flood preparation measures (Dieperink et al. 2018). The preparations that people make to address flood events also represent a protective measure against unexpectedly severe events through the adaption of these individuals' strategies to the evolution of events, as mentioned above. People are the main drivers of social and economic evolution, and they are the key actors in the application of floodability. This also implies the involvement and cooperation of other actors, such as public bodies, citizen organizations, professional associations, commercial and industrial corporations and technical experts. In general, an increase in overall flood awareness is a precondition for the involvement of these different participants in flood risk management. Each of these participants plays a relevant role in the integration of structural mitigation measures with individual and coordinated actions that reduce vulnerability and improve the society's ability to evolve. To organize the participatory process involved in urban flood risk management, the three-point approach proposed by Fratini et al. (2012) proved to be successful in practice as a communication tool for the analysed case study. The proposed methodology of this approach is based on transdisciplinary and multifunctional solutions. The former entail mutual and joint actions between the stakeholders and experts involved, and the latter ideally imply the need for different actors.

In Palazzo (2019), the active participation of all urban actors in the process of the cocreation and co-design of urban projects is considered one of the most promising adaptive strategies for rainwater resilience that incorporates multifunctionality and regenerative urban design. Nevertheless, it is shown by the case studies analysed that this type of cooperation among all actors involved is not accomplished in practice.

\subsection{Identification of Floodability Opportunities}

Bearing in mind the aims of floodability objectives and the general participative framework in which they should be achieved, a technical decision framework is proposed here that conveys decision fluxes in a proper and effective way.

Floodability opportunities must be considered in the framework of a risk management process in which floodability is treated as a group risk treatment option. According to ISO 31000:2018 (2018), risk management is defined as "coordinated activities to direct and control an organization with regard to risk", and it can be viewed as an iterative process that aims to improve and protect the value chain of an organization. Following the ISO 31000:2018 risk management process (Fig. 1), since each specific sector or application of risk management involves particular needs, interlocutors, perceptions and criteria, it is necessary to establish the context of a situation before proceeding to the risk assessment, which consists of the 


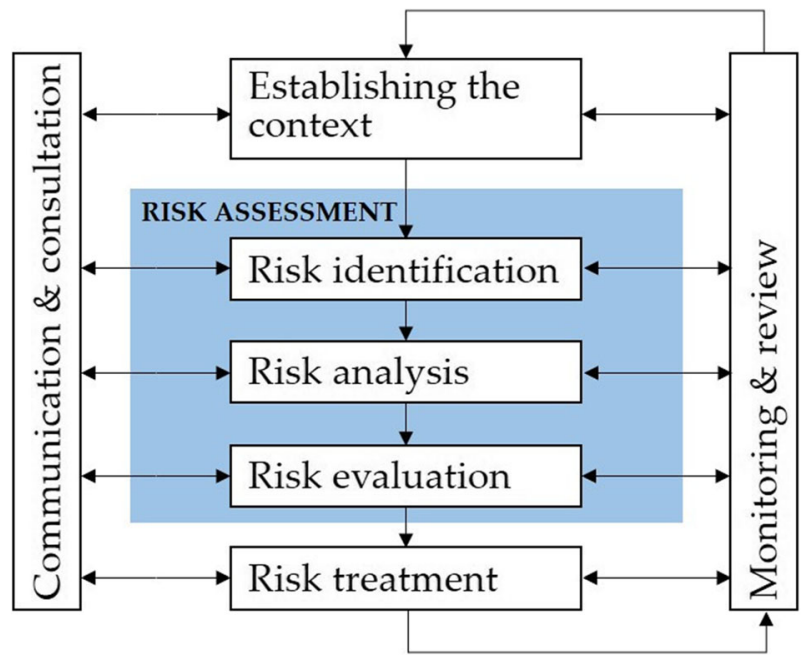

Fig. 1 Risk management process according to ISO 31000:2018

identification, analysis and evaluation of risks. This process also stresses the importance of communication, consultation, monitoring and review to each step.

In the case of floods, the risk in question relies on the probability and magnitude of the natural event and on the features and dimensions of the value that is exposed (Norén et al. 2016).

Flood risk assessment encompasses the estimation of hazards, exposure and vulnerabilities to evaluate the potential effects of a flood with a specific probability (or return period). In the risk identification step, the causes, dimensions and locations of a potential flood are identified. Flood hazard, exposure and vulnerability are assessed and usually depicted by maps; this is a well-established method for this task. The hazard assessment approach usually combines hydrological and hydraulic models. The exposure evaluation finds exposed values, usually by integrating hazard maps and geographical information regarding, for example, land use and critical objects. Finally, several methods (e.g., indices-based models) can be used to investigate vulnerability and consequences, which are considered more extensively in an approach based on flood risk management rather than on flood control.

Once the possible direct and/or indirect damage and the tangible and/or intangible damage have been evaluated, risk treatment is performed by developing strategies for risk mitigation. These mitigation measures can be structural or non-structural (Fletcher et al. 2015). Structural measures include urban stormwater systems, flood defences and embankment systems, while non-structural measures include land use and evacuation planning. From a planning viewpoint, to mitigate against flooding risk and the resulting damage, three different strategies have been suggested (RIBA 2009): remove, defend and adapt.

The removal strategy entails a controlled displacement of critical infrastructures and buildings followed by their resettlement in safer areas. In addition to the high investments that it requires, this strategy may inflict almost entirely unforeseeable consequences on the society, environment and economy. Such an approach does not face the problem; rather, it prevents the need to address similar situations in the future.

The defence strategy prevents an urban settlement from being flooded using measures such as dikes and floodgates that do not allow water to enter an area. These structures are costly and encroaching, inflicting serious impacts on the society and the environment. 
Finally, the adaptation strategy involves the construction of buildings and infrastructures that can withstand the water; floating, amphibious and elevated (on stilts) structures are just some of the possible solutions.

The removal and defence strategies are anchored in traditional urban drainage paradigms (from 1st to 4th, see Novotný (2008) for definitions) and, as discussed before, may play a part in the floodability approach as options limited to unique, strategic, and unadaptable subsystems and services (such as monuments).

To identify floodability opportunities, the "design to resist, pay for damage" approach should be replaced with the following steps that evolve resilient design:

- If possible, reverse the urbanization process: such solutions usually entail high costs, the occupation of large urban areas, a prepared population, cultural changes and societal willingness-to-pay for past unsustainability (i.e., integrated cities - nature is not common in ancient city centres).

- If transformation is not feasible, improve the area's recovery ability: the aim of this approach is not to reduce hazards but to reduce damage and accelerate recovery while progressing towards a resilient system. This approach usually entails lower costs than does the reversion option, is feasible in dense urban areas, is assisted by technologies and strengthens society by attaining its new ability to survive floods (i.e., it reduces fear of catastrophic events).

- If flooding events are frequent, adapt and learn to live with the floods; such floodability measures have similar costs to those of adaptation. This approach is feasible in dense urban areas, but results cannot be achieved if societal behaviour does not change (especially considering that floodability measures may increase local risk). Urban planning must take the presence of flood risk into account; thus, the urban materials used must be different than typical materials. Technology can help with this approach, but the measures used must be robust (i.e., must require low maintenance and maintain efficiency even if electricity or information technology resources are not available), and the population must be prepared for an event because proper behaviour is the first mitigation measure against the damage caused by an event (floodable society).

These steps are not necessarily consecutive, but they can be implemented according to the local economic and societal analyses while bearing in mind that the aim of flood risk management is to reduce the likelihood and/or impact of floods.

The floodability approach introduces the concept of flooding frequency and its technical representations, such as the event return period, not only in its technical design but also in its strategy selection, which shifts from one approach to another depending on these parameters:

- The "live with flood" and "reverse urbanization" approaches are implemented for areas with frequent flooding (up to return period values of 10-20 years);

- The "transform the urban area" approach is used for areas experiencing infrequent events (up to 50 years) to protect the society and economy from relevant damages through the relocation of unique and strategic assets from affected areas;

- The "speed up recovery" approach is implemented in areas experiencing rare events (less frequently than 50 years) to safeguard future urban development of the area and to avoid its abandonment due to large flooding events. 


\subsubsection{Risk Treatment - Reverse the Urbanization Process}

The risk mitigation strategies that could be included in this category belong to the well-known sustainable urban drainage systems (SuDS) and the best management practices (BMPs) approaches.

However, when these techniques are implemented as flood prevention measures (i.e., retention ponds, permeable surfaces and open swales), critical considerations must be taken in regard to vulnerable and physically challenged persons. Moreover, such solutions are known to transform centralized flooding events into a variety of small local episodes due to the runoff from individual SuDS/BMP structures. Usually, such local events are much smaller, and the related damage is usually bearable by the community. Therefore, experts in urban landscaping and social construction must be included in the design process of an urban environment to ensure the fulfilment of all the involved users' needs, and users must be ready to manage local failures and recovery and to prevent social conflicts between the affected communities (i.e., the community solving the flooding problem and the one locally bearing the consequences of a small structural failure).

\subsubsection{Risk Treatment - Improved Recovery}

Resilient mitigation measures aim to reduce damage and to speed up recovery. This type of an approach compensates for the drawbacks of flood control; in particular, it does not transfer the problem to another location within a city via channelization, storage and levees. Since this approach does not consider flood mitigation infrastructures as options, there is no risk of the failure of such structures; this leads to long-term flood risk reduction. All the mitigation measures of this approach are designed to preserve and restore ecological connections to the natural system as a way to accelerate the removal of flood volumes from the urban area. Rapid recovery is usually achieved by ensuring that subsystems and infrastructure are floodproof. Floodproofing encompasses a range of structural and non-structural measures that have the ability, either alone or in combination, to reduce the economic damage of flooding and to accelerate the efficient recovery of sub-systems and services.

The structural measures of this approach are generally small-scale flood protection facilities that reduce the possibility of flood volumes circulating inside buildings, improve the resistance of surfaces to water and sediment movements and make drainage and cleaning after the event simpler and more cost-efficient. Such floodproofing measures are usually performed according to public institutions' technical guidelines or regulations (when available) by building owners.

The non-structural measures of this approach address regulatory and institutional systems. These measures include flood management plans, risk assessments, regulations, stormwater management, wetland protection, flood insurance, funding and subsidies. Moreover, land management and disaster preparedness are used to teach inhabitants to live rationally under the threat of floods.

\subsubsection{Risk Treatment - Adaptation}

Adaptive and learning-by-doing processes are key features of floodable cities. The adaptation as risk treatment causes public spaces to become multifunctional for both social activities and floods: during wet seasons, flood waters can be conveyed and stored in these structures, as they are flexible in operation. Some examples of this treatment are submergible parks or 
pathways, riverside paths and boardwalks. Moreover, the surrounding buildings are elevated, floatable or wet-proof. Additionally, flood preparedness is part of this adaptation.

In the context of flood preparedness information, the proper way in which to act during a flood event is an important issue. This includes learning the safest route from home, keeping a portable radio and flashlights in working order, listening to the local radio or TV for information, keeping the car filled with fuel, staying away from moving water, and not attempting to drive over flooded roads.

\subsection{Examples}

\subsubsection{Venice (Italy): When the Resistance Approach Fails}

Venice is crisscrossed with canals, and it is very sensitive to water levels due to its unique position. The island of Venice experiences flooding when the water level rises in the Venetian lagoon, which is the enclosed bay in which Venice is located. Due to a particular combination of tides, a strong southern wind and a specific movement of the sea waters, an extremely high tide ("Acqua alta") hit Venice on 4 November 1966, causing a 194-cm flood. Unfortunately, such events have become worse and more frequent during the recent decades because of the city's sensitivity to climate change. The island is sinking five times faster than expected, at a rate of $2 \mathrm{~mm}$ per year, partially due to the industrialization of Mestre and Marghera and the increasing removal of water and natural gas from the subsoil.

Recently, in November 2018, Italy was hit by a series of storms that overthrew trees, flooded streets, and resulted in at least 11 deaths (Bendix 2018). In Venice, the water partially submerged some of the famous tourist attractions (Fig. 2), and the city's tourism hotspots were evacuated.

To address such events, in 2003, Italy began building a massive flood barrier designed to isolate the Venetian Lagoon. This project, known as MOSE, is one of the largest civil engineering endeavours in the world (with a cost of $\$ 5.5$ billion) (Fig. 2). The design entails 78 mobile gates stationed at three different inlets. When the tide reaches $110 \mathrm{~cm}$, the gates will rise above the water's surface and prevent the lagoon from flooding. When the tide recedes, these gates fill with water and are thus lowered back in place. This project may be the largest flood resistance project undertaken in Italy during the last 50 years, and it can be considered one of the most prominent examples of the 'design against nature' approach in recent years.

Unfortunately, it has been recently (2019) highlighted that MOSE's underwater structure has eroded due to mould and mussels (Giovannini 2017). A study by CNR (Madricardo et al. 2017), which has updated the map of the lagoon bed, warns that the structures already put in place by MOSE have caused worrisome erosion on the lagoon bed.

As the resistance approach is not able to guarantee safety from flooding, local defences consisting of urban centres within the lagoon have been implemented in conjunction with the construction of MOSE to improve the area's resilience. These measures involve "raising" the quaysides and public paved zones in the lowest-lying parts of the city's urban areas. This process entails complex work to avoid the filtration of water from the subsoil and to secure the ground levels of buildings. The area of Piazza San Marco, which is flooded by even a slightly heavy rain, will be secured soon by the placement of special rubber and metal "caps" in the Basilica that block the entrance of the water from underneath as well as the subsequent raising of the Piazza San Marco paving blocks. Inhabitants are notified of flooding by the city through phone or SMS messaging, but a system of sirens that sound throughout the island is the preferred method of alerting the city in case an Acqua alta is estimated to be particularly high. 

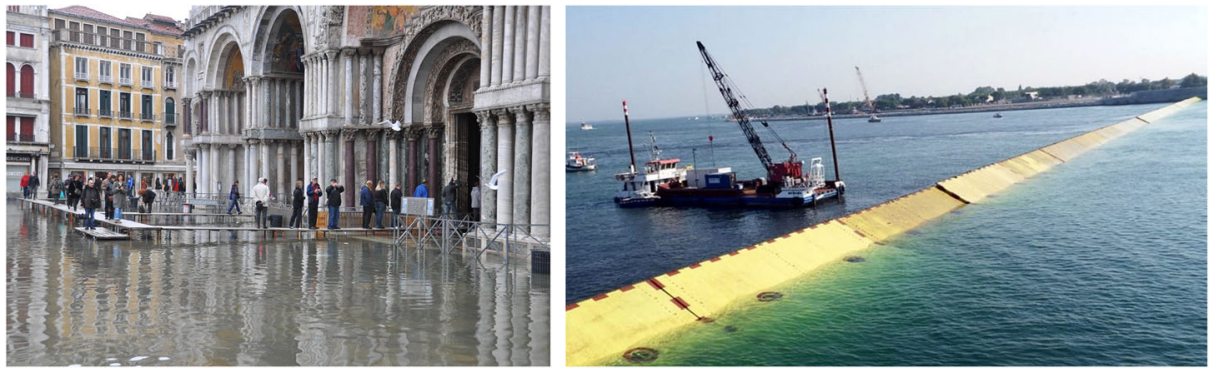

Fig. 2 The Acqua alta in Piazza San Marco (left) and the MOSE flood barrier in Venice, Italy (right)

In summary, to defend Venice from Aqua altas, both structural and non-structural measures have been implemented: from the structural perspective, the MOSE project has encountered many difficulties thus far in terms of reaching the proposed objectives; a local defence consisting of urban centres that protects the city from the standard conditions of an Acqua alta has been constructed, while avoiding the filtration of water from the subsoil.

All these solutions are not able to entirely protect the properties in and population of Venice because of increases in the magnitude and frequency of floods; flooding events occur annually, paralyzing economic activities and damaging buildings and infrastructure.

Additionally, the population has evolved autonomously as the frequency and magnitude of flooding has increased, learning to live with floods and updating their lifestyles and economic activities to accommodate the presence of Aqua altas. Weather forecasts, alert systems, and other emerging techniques and technologies that aim to floodproof houses and protect their ground floors, as well as mobile water barrier protections that can be raised when needed, are among the non-structural and less costly interventions available. In this case, both structural and non-structural measures, including those involving floodability, have been used as integrated adaptation strategies.

The case of Venice presents a relevant example that shows the failure of traditional resistance approaches. Resilience improvement is not able to avoid flooding damage on its own because of the climatic evolution of these events. However, a self-catered floodability approach has been implemented by the population based on an exchange of community knowledge without the involvement of public resources. To improve the defences of Venice, the floodability approach should be formally adopted by the authorities in cooperation with the citizens and economic stakeholders of Venice. Data collection and sharing should be facilitated with the aim of improving the knowledge and organization of the alert system and of providing evacuation routes as well as of identifying locations for key infrastructures.

\subsubsection{Jinhua City (China): Recovering Abandoned Areas and Connecting People}

Over one million people reside in Jinhua city of Zhejiang Province, China. In this city, the southern and northern districts are divided by rivers over $100 \mathrm{~m}$ wide.

Yanweizhou is a wetland (26 ha) located where the Wuyi and Yiwu Rivers intersect to form the Jinhua River. These three rivers separate the communities in the region. Although an opera house and other cultural facilities have been constructed in this area, the inaccessibility that characterizes Yanweizhou prevented it from joining these spaces. In 2013, a landscape project provided a new life to this wetland (Turenscape 2019). This project followed the principles of a resilient landscape and aimed to preserve the riparian habitat while furnishing amenities to the 
residents of the area, to determine an appropriate flood control strategy and to connect the separated communities. The design strategies that were adopted can be summarized as follows: (i) adaptive tactics that preserved and enhanced the remaining habitats; (ii) water-resilient terrain and planting design; (iii) a resilient pedestrian bridge; and (iv) a resilient space for a dynamic experience.

The first strategy concerned the use of the existing riparian sand pits and aimed to preserve their existing vegetation and habitats. Moreover, native wetland species were added to improve biodiversity and provide food for the wildlife. The second strategy was implemented by substituting the concrete floodwalls planned by city authorities with a water-resilient terraced river embankment. The Yanweizhou Park project has implemented the integration of floodable pedestrian paths and pavilions through the planting of terraces, which are closed to people during floods and effectively promote the growth of native tall grasses due to fertile deposits. No irrigation or fertilization is needed. Both the terraced embankment and the inland area are entirely permeable, and they improve the water quality by filtering it through a layer of gravel. When examining the abovementioned resilience-based solutions, the pedestrian bridge included in this infrastructure must be mentioned. This bridge, as a third design strategy, connects the southern and northern city districts and lies above the 200-year flood level. It is adaptive to both the river currents and the people flows. The latter functionality is mainly due to the bridge's many ramps that make access easy from different parts of the city. Finally, several design solutions have been proposed to create an adaptive, dynamic and functional public space for individuals, couples, small groups and large audiences to gather in the case of opera house events (Fig. 3).

This project is a floodable ecological solution that can also be adapted for large-scale flood management.

Being inside the urban area and previously unused by the population, this example shows the added value provided by the floodability approach. In this case, a sustainable approach implies the preservation of an area in its natural state while still implementing a solution, while doing nothing would have no effect on the flooding risk and related damage. The area evolved according to the floodability paradigm, integrating new social and urban functions that were not determined simply by the achievement of environmental aims.

\section{Conclusions and Directions for the Future}

Cities must be resilient to climate change, and protective measures must be taken to prevent against and protect from future floods as well as other natural threats. To build (and retrofit) flood-resilient cities, it is important to evaluate and understand the impacts of floods - even the indirect impacts - at the local level. Adaptation measures require a rigorous urban and site-specific approach, and the related policies cannot be identical for all cities.

A multi-stakeholder perspective must be used to develop a new kind of urban drainage system in which water, land use, ecology, transport, and the nexus between society and economy are jointly considered. Urban planning must integrate stakeholders and authorities, clarifying the responsibilities of the different sectors of cities and planning authorities.

As has already been stressed, systemic vulnerability refers to the fact that some infrastructures and supply flows can considerably affect essential social sectors, such as the health care 


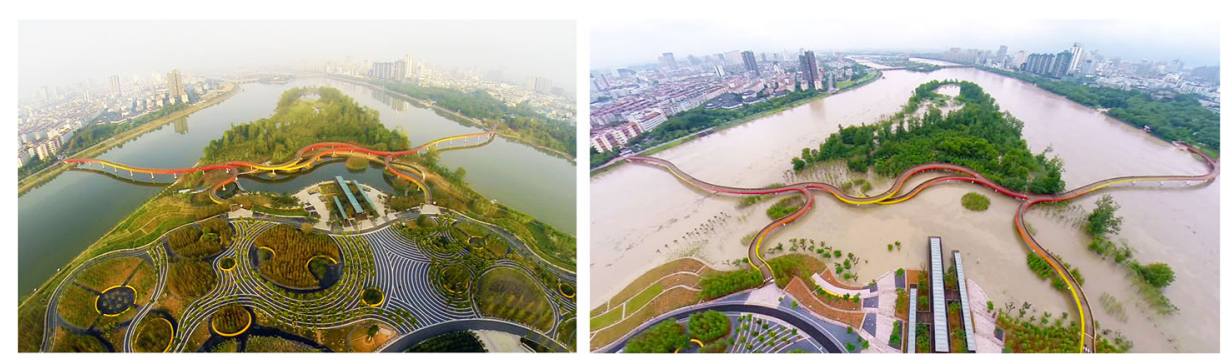

Fig. 3 An aerial view of the park during the dry season (left) and the monsoon season showing a 20-year flood (right) (Turenscape 2019)

sector. For these reasons, efficient simulations that aim to predict and visualize infrastructures must be carried out.

The concept of floodability allows us to address the risk of flooding: flood control is not the only way to achieve flood safety. By increasing their level of floodability, cities could achieve flood safety. Floodability, as mentioned above, can be viewed as a new path towards sustainable urban growth in which flooding can be tolerated and viewed as a driver for societal development. Floodable cities are able to avoid physical damage and socioeconomic disruption during a flood. Due to this feature, floodable cities are more than resilient because their systems do not aim to quickly and efficiently return to their pre-existing equilibria, but they are willing to find new equilibria in which flooding is an event "to live with".

To achieve this ability, a city must be prepared to change its equilibrium as often as necessary. Change cannot be solely technical or infrastructural; rather, it must involve an entire society, as services, functions, land and infrastructure uses will change and may be different in the steady state (i.e., when the flood is not happening) than they are in the event state (i.e., during flooding). Floodability is a progressive change, requires time and cannot be applied to unique vital infrastructures and subsystems; thus, it is not reasonably possible for existing urban settlements to embrace this dynamic equilibrium, at least on the level of the whole system.

Thus, water and urban planning integration are the keys to developing useful strategies that are able to make cities resilient and floodable. Floodability does not introduce new mitigation measures; rather, it provides a new perspective through which it is possible to combine existing measures in a framework that incorporates societal, economic, environmental and technical aspects.

As has been repeatedly stressed, the preparation of society, as well as that of the other stakeholders involved, is important to reduce risk. To enhance the effectiveness of the mitigation measures implemented, collaboration among the stakeholders involved should be facilitated. Moreover, community-based planning should be prioritized to strengthen the community's consensus and their confidence in the risk management process.

In the context of flood risk mitigation strategies, monitoring plays an important role in the organization of alert systems, the provision of information regarding road conditions during floods, the ability to plan evacuation routes, the identification of key infrastructure locations (e.g., hospitals) the verification of the performance of mitigation actions after their realization, and the provision of data to enable storytelling to be used as a learning tool. The data that flow into a city must be used to better understand damage mechanisms, to prevent future damage and to improve citizens' preparation for natural disasters. Modern technologies such as 
contemporary spatial planning techniques, crowdsourced data collection methods and simulation models make it possible to jointly address a large number of societal threats and to optimize solutions that aid citizens in adapting to and learning to live with natural hazards.

Overall, the proposed floodability approach generates the following paradigm shifts in urban drainage design:

- Floodability is an evolution of flood resilience in the sense that, even during flooding, a floodable urban area still retains a sufficient level of liveability and is able to recover its full level of liveability soon after the event.

- The design of floodable urban areas requires that economic and societal activities are mapped to define the areas, paths, activities and services to be defended, relocated, strengthened or dismissed; this process aims to shift the utilized flooding strategies from the preservative approach to the "live with" philosophy.

- The learning-by-doing cycle is the centre of the paradigm, as technical solutions must be implemented with the help of the population who learn from events to better cope with flooding; they first adapt to reduce damage and then change to seek growth. Thus, people's experiences are used to modify the applied strategies, and some actions are abandoned while new actions are implemented.

Acknowledgements Open access funding provided by Università degli Studi di Palermo within the CRUICARE Agreement.

Open Access This article is licensed under a Creative Commons Attribution 4.0 International License, which permits use, sharing, adaptation, distribution and reproduction in any medium or format, as long as you give appropriate credit to the original author(s) and the source, provide a link to the Creative Commons licence, and indicate if changes were made. The images or other third party material in this article are included in the article's Creative Commons licence, unless indicated otherwise in a credit line to the material. If material is not included in the article's Creative Commons licence and your intended use is not permitted by statutory regulation or exceeds the permitted use, you will need to obtain permission directly from the copyright holder. To view a copy of this licence, visit http://creativecommons.org/licenses/by/4.0/.

\section{References}

Assumpção TH, Popescu I, Jonoski A, Solomatine DP (2018) Citizen observations contributing to flood modelling: Opportunities and challenges. Hydrol Earth Syst Sci 22(2):1473-1489

Aven T, Renn O (2009) On risk defined as an event where the outcome is uncertain. J Risk Res 12(1):1-11

Bendix A (2018) A $\$ 6.5$ billion sea wall was supposed to stop Venice from flooding. Now, most of the city is underwater. Business Insider Australia

Coombes PJ, Barry ME (2008) The relative efficiency of water supply catchments and rainwater tanks in cities subject to variable climate and the potential for climate change. Australas J Water Resour 12(2):85-100

Dieperink C, Mees H, Priest SJ, Ek K, Bruzzone S, Larrue C, Matczak P (2018) Managing urban flood resilience as a multilevel governance challenge: an analysis of required multilevel coordination mechanisms. Ecol Soc 23(1):31

Fletcher TD, Shuster W, Hunt WF et al (2015) SUDS, LID, BMPs, WSUD and more - The evolution and application of terminology surrounding urban drainage. Urban Water J 12(7):525-542

Fratini CF, Geldof GD, Kluck J, Mikkelsen PS (2012) Three Points Approach (3PA) for urban flood risk management: A tool to support climate change adaptation through transdisciplinarity and multifunctionality. Urban Water J 9(5):317-331 
Freni G, Liuzzo L (2019) Effectiveness of rainwater harvesting systems for flood reduction in residential urban areas. Water 11(7):1389

Giovannini R (2017) Venice and MOSE: story of a failure. La Stampa 2017

Harvatt J, Petts J, Chilvers J (2011) Understanding householder responses to natural hazards: flooding and sealevel rise comparisons. J Risk Res 14(1):63-83

Holling CS (1973) Resilience and stability of ecological systems. Annu Rev Ecol Syst 4(1):1-23

ISO 31000:2018 (2018) Risk Management - Guidelines. Geneva, Switzerland

La Loggia G, Fontanazza CM, Freni G, Notaro V, Oliveri E, Puleo V (2011) In Urban drainage and sustainable cities: How to achieve flood resilient societies?, WIT Transactions on the Built Environment 203-214

Liao KA (2012) Theory on urban resilience to floods - A basis for alternative planning practices. Ecol Soc 17(4):48

Madricardo F, Foglini F, Kruss A et al (2017) High resolution multibeam and hydrodynamic datasets of tidal channels and inlets of the Venice Lagoon. Sci Data 4:170121

Menoni S, Pergalani F, Boni MP, Petrini V (2002) Lifelines earthquake vulnerability assessment: a systemic approach. Soil Dyn Earthq Eng 22(9):1199-1208

Neville J, Coats G (2009) Urban design and civil society in New Orleans: Challenges, opportunities and strategies in the post-flood design moment. J Urban Des 14(3):309-324

Norén V, Hedelin B, Nyberg L, Bishop K (2016) Flood risk assessment - Practices in flood prone Swedish municipalities. Int J Disaster Risk Reduction 18:206-217

Novotný V (2008) A new paradigm of sustainable urban drainage and water management, Oxford roundtable workshop on sustainability, 10-15 August 2008; Oxford University

Palazzo E (2019) From water sensitive to floodable: defining adaptive urban design for water resilient cities. J Urban Des 24(1):137-157

Pasi R (2016) Flood impact over urban systems. How to assess (and manage) urban vulnerabilities to adapt spatial planning practices at the municipal scale. $\mathrm{PhD}$ Thesis. Università degli Studi di Venezia

Pasi R, Viavattene C, La Loggia G, Musco F (2018) Assessing urban system vulnerabilities to flooding to improve resilience and adaptation in spatial planning. In: Bisello A, Vettorato D, Laconte P (eds) Smart and Sustainable Planning for Cities and Regions. SSPCR 2017. Green Energy and Technology. Springer, Cham

RIBA (2009) Building future: Facing up to Rising Sea Levels. Attack, retreat or defend? The choices facing those fighting rising sea levels. ICE, Institution of Civil Engineering, London

Roder G (2019) Flood dynamics, social vulnerability and risk perception: challenges for flood risk management. $\mathrm{PhD}$ Thesis. Università degli Studi di Padova

Sdao F, Sivertun A, Sole A, Albano R, Pascale S, Giosa L (2013) A GIS Implementation of a Model of Systemic Vulnerability Assessment in Urbanized Areas Exposed to Combined Risk of Landslide and Flood. In Geographic Information Analysis for Sustainable Development and Economic Planning: New Technologies, Borruso G, Bertazzon S, Favretto A, Murgante B, Torre CM Eds. IGI Global: Hershey, PA, USA, 274-294

Serre D, Barroca B, Balsells M, Becue V (2018) Contributing to urban resilience to floods with neighbourhood design: the case of Am Sandtorkai/Dalmannkai in Hamburg. J Flood Risk Manag 11(S1):S69-S83

Siegrist M, Gutscher H (2008) Natural hazards and motivation for mitigation behavior: People cannot predict the affect evoked by a severe flood. Risk Anal 28(3):771-778

Sörensen J, Persson A, Sternudd C et al (2016) Re-thinking urban flood management-Time for a regime shift. Water 8(8):332

Turenscape A (2019) Resilient Landscape: Yanweizhou Park in Jinhua City. Available on line: http://www. landezine.com/index.php/2015/03/a-resilient-landscape-yanweizhou-park-in-jinhua-city-by-turenscape/. Accessed 8 Nov 2019

Viero DP, Roder G, Matticchio B, Defina A, Tarolli P (2019) Floods, landscape modifications and population dynamics in anthropogenic coastal lowlands: The Polesine (northern Italy) case study. Sci Total Environ 651: $1435-1450$

Publisher's Note Springer Nature remains neutral with regard to jurisdictional claims in published maps and institutional affiliations. 